\title{
Changing Practices Amid COVID-19 Pandemic: Lessons Learnt During a Review and Planning Meeting For Neglected Tropical Disease Control Programing in Ekiti State, Nigeria
}

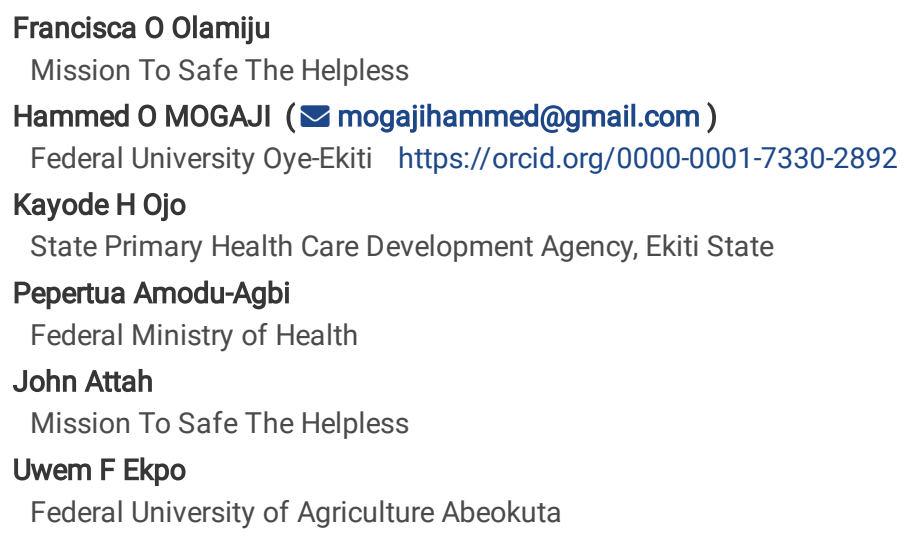

Research note

Keywords: COVID-19, NTD, adequate handwashing facilities, hand-washing, mass gatherings, subsequent meetings

Posted Date: March 22nd, 2021

DOI: https://doi.org/10.21203/rs.3.rs-322298/v1

License: (c) (i) This work is licensed under a Creative Commons Attribution 4.0 International License. Read Full License 


\section{Abstract}

Objectives: Review meetings are critical activities aiding successful implementation of mass administration of medicines (MAM) for Neglected Tropical Diseases (NTD) control. The objective of this study was to assess the changes in practices amid COVID-19 pandemic during the review and planning meeting for 2020 MAM.

Results: A total of 42 NTD implementers participated in this study [59.5\% females and $40.5 \%$ males]. Majority of the participants were Local Government NTD (LNTD) coordinators (40.48\%), State NTD officers (26.19\%), LGA NTD data managers (23.81\%) and NGDO partners (4.76\%). Majority of the participants expressed their level of satisfaction on these modes of invitation (97.5\%), admission (92.5\%) and coordination (97.5\%) during the meeting. Our findings have shown the importance of online platforms such as WhatsApp groups and email as communication channels between programmers involved in NTD control. Furthermore, compliance level to WHO guidelines were optimal for venue spacing (100\%), usage of facemasks (85\%) and physical distancing (72.5\%), but sub-optimal for hand-washing (67.5\%) and respiratory etiquette (52.5\%). There were gaps in the provision of adequate handwashing facilities for the attendees. There is a need for more refined guidelines to steer investments in the provision of adequate hand-washing points in consideration of the population during subsequent meetings or mass gatherings.

\section{Introduction}

Nigeria reported its first COVID-19 case on the 27th of February 2020, and has a total of 59,738 cases after 8 months, with the virus spreading to all the 37 states. Ekiti State ranks $25^{\text {th }}$ in terms of prevalence with a total of 386 confirmed cases and 6 deaths as of December $9^{\text {th }}, 2020$ [1]. In response to the pandemic, the Nigerian government imposed a lockdown order on March 31, 2020 placing restrictions on social gatherings and other community-based activities. These restrictions had put on hold planning for, and implementation of Neglected Tropical Diseases (NTDs) control programme.

Neglected tropical diseases (NTD) affects more than 1 billion people worldwide, placing an enormous health and socio-economic burden on people living in poor and marginalized communities [2]. Over 500 million affected people reside in sub-Saharan Africa (SSA) with Nigeria bearing about $25 \%$ of Africa's NTD burden $[2,3,4]$. Similar to other infectious diseases control programs like nets distribution and immunization campaigns, NTD control or elimination requires huge investments, rigorous planning and resource distribution. The World Health Organization (WHO) recommends periodic largescale administration of efficacious, safe, and inexpensive drugs without a prior diagnosis to at-risk populations in endemic areas [5]. This strategy known as Mass Administration of Medicines (MAM) could be implemented either once a year (annually), twice in a year (biannually), or once in two years (biennially) depending on the prevalence of infection in the community [6]. It is therefore not an uncommon practice to hold regional meetings amongst major stakeholders to review immediate past MAM activity and discuss implementation bottlenecks with a view of providing solutions and understanding what works best.

From an organizational perspective, review meetings are considered a critical activity in the planning and implementation of MAM in Nigeria. It is a systematic and objective process of evaluating key performance indicators from NTD programmers across different Local Government Area (LGAs) in Nigeria. Such evaluation aims to understand factors aiding or hindering higher levels of therapeutic and geographic coverage during MAM, and recommending solutions to the identified bottlenecks while promoting the adaptation of what works best. Typical with most review meetings, is the gathering of stakeholders at a particular spot over an extended period of time. However, with the advent of COVID-19 pandemic, it becomes imperative to hold such meetings in-line with WHO recommended guidelines on public gathering amid COVID-19 pandemic [7,8].

The Ekiti State Neglected Tropical Diseases Unit of the State Primary Health Care Development Agency (SPHDA) in collaboration with the Mission to Save the Helpless (MITOSATH) and Federal Ministry of Health (FMOH) organized a meeting to review 2019 MAM activities and prepare a workplan for 2020 MAM activities in Ekiti State. This study, therefore, assessed the changes in practices amid COVID-19 pandemic via-a-vis level of compliance to best practices for preventing COVID-19 transmission and participants' satisfaction regarding coordination, resource allocation and safety assurances.

\section{Methods}

\section{Study area}

This study was carried out in Ekiti State, one of the six southwestern states in Nigeria. It has 16 Local Government Areas (LGAs) with Ado-Ekiti as the capital (Figure S1). The state is endemic for four major preventive chemotherapy NTDs including Onchocerciasis, Lymphatic Filariasis, Schistosomiasis and Soil Transmitted Helminthiasis.

\section{Questionnaire Administration}

This study was cross-sectional in design involving the administration of semi-structured questionnaires to collect both quantitative and qualitative data. The questionnaire was administered to study participants during the review meeting (precisely at a more convenient time such as tea/lunch break session). Information such as participants' demographic data, and opinions about the meeting vis-à-vis coordination, resource allocation and safety assurances were collected. Secondly, a rapid questionnaire was used to assess the level of compliance during the operational phase of the meeting with the WHO recommended guidelines for public gatherings during COVID-19 pandemic [9]. Assessments were made in categories which include;(1) moderation related to the venue (2) moderation related to the participants (3) moderation related to the duration of the event. All assessments were conducted in the English language by two data collectors. 
A total sampling of all invited stakeholders was employed. Only attendees who have experienced or participated in 1or more previous review meetings for NTD control programming were recruited into the study. Samplings was done systematically as the participants were seated and effort were made to recruit all participants except those who did not consent to the study procedures. Caution was also taken not to allow the questionnaire completion affect participants' participation at the meeting.

\section{Data collection, processing and analysis}

Data obtained from this study were entered into Microsoft Excel 2019 software. Quantitative data were analyzed using descriptive statistics in SPSS. 20.0. Qualitative data obtained through open-ended questionnaires were analyzed thematically following standard data analysis steps.

\section{Results}

\section{Demography}

A total of 42 attendees who were NTD practitioners across the 16 LGA in Ekiti State participated in this study, 25(59.5\%) were females and 17(40.5\%) were males (Table S1) (Figure S1).

\section{Level of compliance to WHO guidelines for public gathering during COVID-19 pandemic}

The level of compliance to WHO recommended guidelines for public gathering during COVID-19 pandemic was assessed during the operational phase of the meeting. As regards the venue of the meeting, the compliance level was $50 \%$. The meeting was held indoor and was completely a physical meeting. Also, there were no regular and thorough cleaning and disinfection of the venue by a designated staff during the period of the meeting. Two-third $(66.67 \%)$ of the modifications required for the participants were met. This includes advising people to observe physical distancing and instructing those with a higher risk of transmitting COVID-19 not to attend. The modifications required for the duration of the meeting was not met as the meeting took more than 5 hours (Table 1). Table 2 presents the changes in practices during the review meeting as compared to previous review meetings.

\section{Participants' satisfaction regarding coordination and adherence to best practices for the prevention of COVID-19 during the review meeting}

About $98 \%$ participants' satisfaction were attributed to the fact that the invitation offered them opportunity for capacity building in NTDs programming (Table 3).

\section{“...it will build my capacity for NTD programming”- (Participant, Irepodun/ifelodun)}

“to update my knowledge about NTD and plan for 2020"- (Participant, Ekiti East)

Also, there were satisfactions ascribed to timely notification of the meeting through newly created online platforms such as Whatsapp and email.

"the notification for the meeting came earlier because of the prior information"- (Participant, ljero)

"modern way of invitation in that a Whatsapp platform was created for participants" - (Participant, Ado)

Similarly, about $65 \%$ of the attendees agreed that the review meeting is different from that of the previous year as it combined both review of the previous years' MAM and the planning for the year's MAM (Table 3). Other comparisons were in terms of a more conducive environment, abiding with all COVID-19 regulations and early notification about the meeting which allowed the participants to have adequate time to prepare.

"last year was only a review meeting of 2018 but this year was both a review meeting and plan for 2020 Workplan"-(Participant, Irepodun/ifelodun)

"We have a very conducive environment"-(Participant, IdoOsi)

"notification came earlier and there was adequate preparation for it"- (Participant, ljero)

On the other hand, majority of the attendees (92.5\%) expressed their level of satisfaction about the mode of admission and coordination during the review meeting (Table 3). These satisfactions were attributed to spacious and well-ventilated venue, in addition to the COVID-19 precautionary measures put in place by the organizers (Table 3)

“...before you enter into the venue, you should wash your hand with water and soap, sanitizer your hand too"- (Participant, Ado)

"I saw the MITOSATH people fumigating their materials before the commencement of the meeting- (Participant, Ekiti East)

“...the venue...it allows members to space themselves, the use of face mask was done and provision of sanitizer"- (Participant, Gboyin)

Usage of face mask was on top of the priority list of best practices during the meeting, with $85 \%$ of the participant adhering to it, this was followed by maintaining physical distancing (72.5\%), hand hygiene measures including washing and sanitizing (67.5\%) and respiratory etiquette (52.5\%) (Table S2). In addition, majority of the participant felt there were no challenges that could expose them to COVID-19 during the period of the review meeting. One of 
the major reason was the fact that the venue for the meeting was spacious and rules guiding the organization of meetings during COVID-19 pandemic was adhered to (Table S2).

"The place is well okay for everyone and COVID-19 rule was strongly observed" (Participant, Ido-osi)

"COVID-19 rules were followed if not attendees health would have been in danger" (Participant, Ikere)

"No challenge so far as the hall used for the programme is big enough for spacing"- (Participant, Irepodun/Ifelodun)

\section{Discussion}

Beyond the aim of assessing implementation progress and addressing associated bottlenecks [11], our findings emphasized the importance of review meetings in building capacities of programmers which is expected to translate into efficient performance during the MAM process. Also, our findings highlight the importance of using online platforms (WhatsApp groups and email) in establishing contacts with programmers. Majority of the participants expressed their level of satisfaction on these modes of engagement as it is modern and more flexible medium of communication that gives them prompt access to information, compared to the traditional paper-based channel of communication through their LNTD coordinators. These findings corroborate with those of Kamel Boulus et al. [12], HIFA [13] in Uganda and Woods et al. [14] in South Africa. Including WhatsApp to the communication and teaching toolbox would facilitate timely responses among programmers, ensure wider dissemination of public health messages to more people and help create virtual communities of enquiry and practice [12].

With the advent of COVID-19 and the consequent regulations guiding the conduct of public meetings, the first phase of this study investigated the level of compliance of the NTD review and planning meeting with WHO recommended guidelines. Generally, the compliance level was optimal for the usage of facemasks and physical distancing. This was reiterated by the study participants who expressed their satisfaction with the mode of admission and coordination during the meeting. However, compliance levels were sub-optimal, most especially for modifications related to the venue and duration of the event. There were gaps in the provision of regular and thorough disinfection of the venue during the period of the meeting.

Furthermore, before the outbreak of COVID-19 pandemic, the importance of WASH (water, sanitation and hygiene) has been acknowledged through the $6^{\text {th }}$ Sustainable Development Goal (SDG) which is aimed at "Ensuring availability and sustainable management of water and sanitation for all" with three specific health targets by 2030. Hand washing is one of the most important components of WASH resource programming been advocated by UNICEF. The presence of handwashing facilities with soap and water on-premises has therefore been identified as the priority indicator for global monitoring of hygiene under the SDGs [15]. However, findings from our study revealed that only one hand washing facilities (i.e. 1 veronica bucket with water, 1 soap and 1 sanitize) were provided at the entrance of the venue for the over 50 participants at the venue. The current WHO guidelines for handwashing during public gatherings amid COVID-19 pandemic have focused more on availability of handwashing facilities, with little or no emphasis on the adequacy of such facilities as the number of the participants in the gathering increases. There is thus need to review such guideline in line with the conditions previously described by Adams et al. [16].

\section{Conclusion}

Our findings have shown the importance of review meetings and as well highlighted new communication channels to be explored between programmers involved in NTD control. However, there is a need for more refined guidelines to steer investments in the provision of adequate hand-washing points.

\section{Limitations}

Restriction orders enforced on public gatherings in some states in the country limits our sampling methodology, hence our findings should be used with caution.

\section{Abbreviations}

MAM: Mass Administration of Medicines

NTD: Neglected Tropical Diseases

NGDO: Non-Governmental Development Organization

WHO: World Health Organization

COVID-19: 2019 Novel Coronavirurs

MITOSATH: Mission To Safe the Helpless

LGA: Local Government Areas 
LNTD: Local Neglected Tropical Diseases Coordinator

SNTD: State Neglected Tropical Diseases Coordinator

SPHDA: State Primary Health Care Development Agency

FMOH: Federal Ministry of Health

SSA: Sub Saharan Africa

\section{Declarations}

\section{Ethics approval and consent to participate}

This study received ethical approval from the State Primary Health Care Development Agency, Ekiti State, Nigeria. However, before the commencement of the study, the study procedures were announced to all attendees and those willing to participate in the study were given printed consent forms to complete. Each participant provided written consents.

\section{Availability of data and material}

Datasets obtained and generated during the study is available as supplementary file

\section{Funding}

Funding for this study was provided by MITOSATH, Jos.

\section{Acknowledgements}

We would like to thank to study participants for their cooperation during data collection process.

\section{Consent for publication}

Not applicable

\section{Competing interests}

The authors declare that they have no competing interests.

\section{Author's contributions}

FOO and HOM conceived the study. HOM and UFE designed the study plan. HOM and JA collect field data and carried out the statistical analysis. HOM wrote the first draft of the manuscript. All authors read and approved the final manuscript.

\section{References}

1. National Centre for Disease Control (NCDC). COVID-19 Nigeria. [Online] [Accessed on $9^{\text {th }}$ Dec 2020]. Available at https://covid19.ncdc.gov.ng/

2. Hotez PJ, Kamath A. Neglected tropical diseases in Sub-Saharan Africa: review of their prevalence, distribution, and disease burden. PLoS Neg Trop Dis. 2009; doi:10.1371/journal.pntd.0000412.

3. Molyneux DH, Hotez PJ, Fenwic A. "Rapid-impact interventions": how a policy of integrated control for Africa's neglected tropical diseases could benefit the poor. PLoS Med. 2005;2(11): e336. doi:10.1371/journal.pmed.0020336.

4. Hotez PJ, Asojo OA, Adesina AM. Nigeria: "Ground Zero" for the high prevalence neglected tropical diseases. PLoS Neg/ Trop Dis. 2012;6: e1600.

5. World Health Organization (WHO). Regional Office for the Western Pacific: Neglected Tropical Diseases. 2012; WPR/RC63/6.

6. World Health Organization (WHO). Preventive chemotherapy in human helminthiasis: coordinated use of anthelminthic drugs in control interventions:a manual for health professionals and programme managers. World Health Organization, Geneva 2006.

7. World Health Organization (WHO). Regional Office for the Western Pacific: Neglected Tropical Diseases. 2012; WPR/RC63/6.

8. Flaxman S, Mishra S, Gandy A, Unwin JT, Coupland H, Mellan TA, et al. Estimating the number of infections and the impact of non-pharmaceutical interventions on COVID-19 in 11 European countries. Imp Coll London [Internet]. 2020 [cited 2020 Apr 25];(March):1-35. Available from: https://doi.org/10.25561/77731

9. World Health Organization (WHO). COVID-19: WHO issues interim guidance for implementation of NTD programmes. [Internet]. [cited 2020 May 31] Available from:https://www.who.int/neglected_diseases/news/COVID19-WHO-interim-guidance-implementation-NTD-programmes/en/

10. World Health Organization (WHO). Key planning recommendations for mass gatherings in the context of COVID-19. Interim guidance.WHO/2019nCoV/POE_mass_gathering/2020.3. Available at https://www.who.int/publications/i/item/10665-332235 [cited 18 August 2020] 
11. National Action Plan for Health Security (NAPHS) National Action Plan for Health Security Federal Republic of Nigeria (2018-2022). [Online] [Accessed October 2018] Available at

https://extranet.who.int/sph/sites/default/files/donor_partner_landscape/Nigeria\%20National\%20Action\%20Plan\%20for\%20Health\%20Security.pdf

12. Kamel Boulus MN, Giustini DM, Wheeler S. Instagram and WhatsApp in Health and Healthcare: An Overview. Future Internet. 2016;8:37; doi:10.3390/fi8030037

13. Healthcare Information For All (HIFA). Using WhatsApp to connect Community Health Workers in Uganda with the global HIFA community. [Online] [Accessed October 2018]. Available at https://www.hifa.org/news/using-whatsapp-connect-community-health-workers-uganda-global-hifacommunity-0

14. Woods J, Moorhouse M, Knight L. A descriptive analysis of the role of a WhatsApp clinical discussion group as a forum for continuing medical education in the management of complicated HIV and TB clinical cases in a group of doctors in the Eastern Cape, South Africa. S Afr J HIV Med. 2019; 20(1), a982. https://doi.org/10.4102/sajhivmed.v20i1.982

15. WHO and UNICEF. Progress on drinking water, sanitation and hygiene: 2017 update and SDG baselines. Geneva: World Health Organization. 2017 Licence: CC BY-NC-SA 3.0 IGO

16. Adams J, Bartram J, Chartier Y, Sims J. Water, Sanitation and Hygiene Standards for Schools in Low-cost Settings, World Health Organization, 2009; Geneva, Switzerland

\section{Tables}

Table 1: Level of compliance to WHO guidelines for public gathering during COVID-19 pandemic

\section{Prevention and control measures applicable during the operational phase of the meeting}

\section{Modifications of the meeting (related to the venue)}

Hosting the event, at least partially, online/remotely/virtually

Hosting the event outdoors rather than indoors

0

Adjusting the official capacity of the venue

Ensuring availability of hand-washing facilities with soap and water and/or hand rub dispensers

1

Ensuring regular and thorough cleaning and disinfection of the venue by designated staff

Regulating the flow and density of people entering, attending, and departing the event

0

Total

Modifications of the meeting (related to the participants)

Advising people to observe physical distancing, respiratory/cough etiquette, and hand hygiene practices

1

Advising people with a higher risk of transmitting COVID-19 that they should not attend the event

Advising people with a higher risk of developing severe illness from COVID-19 (that they should not attend the event, or making special arrangements for them

Total

Modifications of the meeting (related to the duration)

Keeping the duration of the event to a minimum to limit contact among participants

A score of 1 denotes that the meeting met the WHO recommended guidelines, while Odenotes that the guideline was not met.

Table 2: Changing practices during the 2020 review and planning meeting for NTD control programming in Ekiti State Nigeria. 


\begin{tabular}{|c|c|c|c|}
\hline Practices & $\begin{array}{l}\text { Previous review } \\
\text { meetings before COVID- } \\
19 \text { pandemic }\end{array}$ & Current review meeting during COVID-19 pandemic & $\begin{array}{l}\text { Cost- } \\
\text { implication }\end{array}$ \\
\hline Number of Participants & 65 & 57 & $15 \%$ increment \\
\hline \multicolumn{4}{|l|}{ Duration of the event } \\
\hline \multirow[t]{2}{*}{$\begin{array}{l}\text { Venue moderations (size/capacity and other } \\
\text { moderations) }\end{array}$} & Less moderation & $\begin{array}{l}\text { (a)Physical distancing via modified sitting } \\
\text { arrangement }\end{array}$ & $\begin{array}{l}70,0000 \text { naira } \\
(\$ 160)\end{array}$ \\
\hline & & $\begin{array}{l}\text { (b) Sharing of items or materials was discouraged } \\
\text { and prohibited (c) A large hall was used }\end{array}$ & \\
\hline \multirow[t]{2}{*}{ Use of Personal Protective Equipment (PPE) } & None & $\begin{array}{l}\text { (a) Face masks was given to each of the study } \\
\text { participants }\end{array}$ & $\begin{array}{l}400 \text { naira }(1 \\
\text { dollar per }\end{array}$ \\
\hline & & (b) Hand sanitizers were given to each participant. & \\
\hline \multirow[t]{2}{*}{$\begin{array}{l}\text { Other protocols for preventing spread of } \\
\text { COVID- } 19 \text { such as handwashing and use of } \\
\text { sanitizers }\end{array}$} & None & $\begin{array}{l}\text { (a) Hand washing by participants before entering } \\
\text { meeting venue, (b) Screening body temperature of } \\
\text { participants }\end{array}$ & \\
\hline & & (c) Use of hand sanitizers & \\
\hline Communication & $\begin{array}{l}\text { Use of public address } \\
\text { systems }\end{array}$ & No public address systems was used & $\mathrm{N} / \mathrm{A}$ \\
\hline
\end{tabular}

Table 3: Participants' satisfaction regarding invitation, admission and overall coordination during the review meeting

\begin{tabular}{|c|c|c|}
\hline Attendee's level of satisfaction & Frequency & Percentage \\
\hline \multicolumn{3}{|c|}{ Are you satisfied with how you were invited to this meeting } \\
\hline Yes & 39 & 97.5 \\
\hline No & 1 & 2.5 \\
\hline \multicolumn{3}{|c|}{ Is there a difference between the mode of invitation compare to that of previous years } \\
\hline Yes & 26 & 65.0 \\
\hline No & 11 & 27.5 \\
\hline Don't know & 3 & 7.5 \\
\hline \multicolumn{3}{|c|}{ Are you satisfied with how you were admitted into the meeting venue } \\
\hline Yes & 37 & 92.5 \\
\hline No & 2 & 5.0 \\
\hline Don't know & 1 & 2.5 \\
\hline \multicolumn{3}{|c|}{ Is there a difference between the mode of admission compared to that of previous years } \\
\hline Yes & 20 & 50.0 \\
\hline No & 13 & 32.5 \\
\hline Don't know & 7 & 17.5 \\
\hline \multicolumn{3}{|c|}{ Are you satisfied with how you were coordinated in the meeting } \\
\hline Yes & 39 & 97.5 \\
\hline No & 1 & 2.5 \\
\hline \multicolumn{3}{|c|}{ Is there a difference between the mode of coordination compared to that of previous years } \\
\hline Yes & 29 & 72.5 \\
\hline No & 2 & 5.0 \\
\hline Don't know & 9 & 22.5 \\
\hline
\end{tabular}

\section{Supplementary Files}

This is a list of supplementary files associated with this preprint. Click to download. 
- FigureS1.tiff

- Tables1.docx

- Tables2.docx 